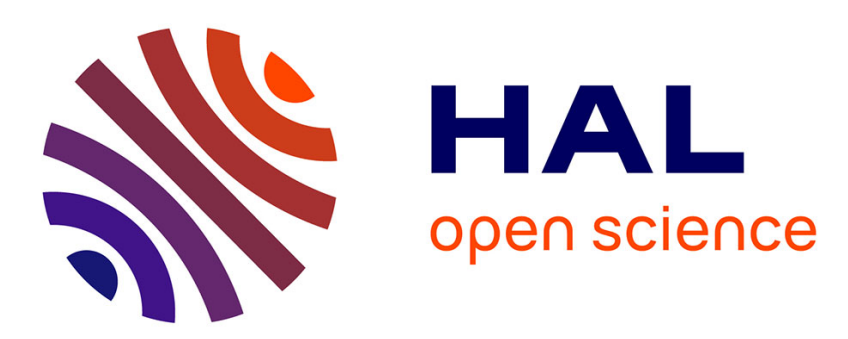

\title{
Plasma sprayed thermal barrier coatings for industrial gas turbines: morphology, processing and properties
}

\author{
H. Grünling, W. Mannsmann
}

\section{To cite this version:}

H. Grünling, W. Mannsmann. Plasma sprayed thermal barrier coatings for industrial gas turbines: morphology, processing and properties. Journal de Physique IV Proceedings, 1993, 03 (C7), pp.C7903-C7-912. 10.1051/jp4:19937140 . jpa-00251762

\section{HAL Id: jpa-00251762 https://hal.science/jpa-00251762}

Submitted on 1 Jan 1993

HAL is a multi-disciplinary open access archive for the deposit and dissemination of scientific research documents, whether they are published or not. The documents may come from teaching and research institutions in France or abroad, or from public or private research centers.
L'archive ouverte pluridisciplinaire HAL, est destinée au dépôt et à la diffusion de documents scientifiques de niveau recherche, publiés ou non, émanant des établissements d'enseignement et de recherche français ou étrangers, des laboratoires publics ou privés. 


\title{
Plasma sprayed thermal barrier coatings for industrial gas turbines: morphology, processing and properties
}

\author{
H.W. GRÜNLING and W. MANNSMANN
}

ABB Kraftwerke AG, Kallstadter Str. 1, 6800 Mannheim 31, Germany

\begin{abstract}
Thermal barrier coatings out of fully or partially stabilized zirconia offer a unique chance in gas turbines to increase the gas inlet temperature significantly while keeping the temperature of the structural material of the component within conventional limits. The protection of combustor parts and transition pieces as well as of some stationary gas turbine parts however is state of the art. As a consequence of still insufficient reliability, the application for hot rotating parts is very limited. The introduction as a design element requires safe life within defined time intervals. These depend on the overhaul and repair intervals of the engines. For large land based industrial or utility gas turbines, for example, coating life between 25.000 and $30.000 \mathrm{hrs}$. is a minimum requirement. Premature failure of a coating by e.g. local spalling causes local overheating of the component with the consequence of its total destruction or even more expensive secondary damages.
\end{abstract}

Life limiting is the corrosion rate at the ceramic-metal interface and the behavior of the coated system under transient operating conditions, where multiaxial strain and stress distributions are generated. Sufficient strain tolerance of the coating both under tensile as well as compressive conditions is required.

The properties of thermal barrier coating systems depend strongly on the structure and phase composition of the coating layers and the morphology of and the adhesion at the ceramic-metal interface. They have to be controlled by the process itself, the process parameters and the characteristics of the applied materials (e.g. chemical composition, processing, morphology, particle size and size distribution). It will be reviewed, how properties and structures of coating systems correlate and how structures can be modified by careful control of the process parameters. 


\section{INTRODUCTION}

Ceramic protective coatings for rocket and turbine applications have been mentioned in the technical literature since the late 1940s [1-4]. Thermal barrier coatings based on fully and later on partially stabilized Zirconia have been under investigation since about 30 years $[5,6]$.

The most interesting technical application is its use as a heat resistor in order to control the heat transfer through a cooled wall of a hot component. Large temperature differences can be achieved with coating thicknesses of only a few 10 to 100 microns [7]. So these coatings can be used as an additional measure to increase the surface temperature of hot gas path components in gas turbines compared to more heat resistant materials or more efficient cooling techniques. In combination with advanced materials and/or cooling techniques the gas inlet temperature and therefore the efficiency of a gas turbine can be increased significantly (Fig. 1) [8].

The application of thermal barrier coatings for combustor parts, augmentors, transition pieces and, more recently, stationary turbine components today is state of the art. There are also some attempts made to apply them for hot rotating parts. The use on noncritical turbine components or components with conventional surface temperatures has provided substantial improvements in system performance through increased turbine efficiency, reduction in maintenance requirements and fuel consumption. However, the use as a design element for maximum component surface temperature is still a matter of investigation and development. The required reliable safe life within defined time intervals can only be achieved through a complete understanding of all factors necessary to achieve or affect life under thermal, thermomechanical and mechanical loading.

The following paper summarizes some recent work on how to achieve reliable and safe thermal barrier coatings. The authors concentrate upon plasma sprayed duplex TBC-systems for industrial gas turbine applications, since that is a field of their own expertise.

\section{REQUIREMENTS AND LOAD CHARACTERISTICS}

The requirements for the application of TBCs on hot components of industrial gas turbines can directly be derived from the operation conditions and loads of the components to be coated. They strongly depend from the hot gas temperature, the maximum useful operation temperature of the component material and the cooling efficiency which determines the maximum temperature difference between the hot gas and the surface of the component. Some data for conditions to be realized in advanced gas turbines are given in [9]. Some important requirements for an application of a TBC as a design element are given in table 1 . These requirements are not easily translatable into required properties of a ceramic material. The complete system which consists of the ceramic top layer, a metallic bond coat and the structural material has to be considered. This system is loaded mechanically (centrifugal forces, gas flow etc.), thermally (hot gas, cooling air), and thermomechanically (transients). The strain history of the component is very much determined by the reaction and therefore the properties of the structural material, as well. Additional loads within the coatings and in the structural material result from the thermal gradient in the ceramic and the mismatch of physical properties of the partners in the system. They create additional strains and stresses, which determine the behavior and life of the coatings. A typical strain cycle for the ceramic coating under transient conditions showed to be between approx. $+0,5 \%$ and $-0,3 \%$ [10]. The strain cycles will of course be influenced by residual strains (or stresses) within the coatings. They can be compressive as well as tensile, resulting from processing or differences in the properties as mentioned above. This has to be taken into account for life considerations and optimization strategies.

\section{COMPOSITION, MORPHOLOGY AND PROPERTIES}

\subsection{Composition of the Ceramic Coating}

The composition of zirconia ceramics with respect to phase composition, morphology and mechanical properties is well investigated. Important for optimization of the mechanical properties is the polymorphic transformation of pure and partially stabilized zirconia. For optimum thermomechanical and chemical stability at high temperatures, yttria proved to be the best stabilization addition for TBC applications [11-14]. Partial stabilization in the range between 6-8 wt-\% yttria reveals the best cyclic behavior under high temperature conditions $[15,16]$. Important for achieving excellent fracture toughness of the ceramic coating is the predominance of a nonequilibrium tetragonal phase called $t^{\circ}$, which forms through a displacive transformation of the cubic $\mathrm{ZrO}_{2}$ during rapid cooling rates of $10^{6}$ to 
$10^{7} \mathrm{~K} / \mathrm{s}$ in the composition range for partially yttria stabilization $[17,18]$. This phase may exist with different yttrium content, depending from thermal history, [19]. It transforms diffusion controlled into the equilibrium phases at temperatures above about 1100 to $1200^{\circ} \mathrm{C},[17,18]$. The excellent fracture toughness was explained to be the result of a microstructure consisting of $t$-twins, anti phase boundaries and a "tweed"-structure [20].

It is also important to consider the influence of impurity elements on the stability and phase transformation as well as sintering processes. In the high temperature range of application, i.e. $>1000$ to $1200^{\circ} \mathrm{C}$, volume shrinkage resulting from sintering can affect thermal stability and cyclic durability dramatically. Sintering studies showed a pronounced effect of silicon additions on sintering kinetics and shrinkage starting within the above given temperature range [21].

\subsection{Composition and Interface Properties of the Bond Coat}

The task of the bond coating is to provide:

- $\quad$ A fit between the ceramic TBC and the metallic structure as a buffer.

- Sufficient adhesion between ceramic and metal.

- Good oxidation and hot corrosion resistance to the system.

Optimum life requires a composition which provides an alumina scale growing as slow as possible at the interface. However, growth kinetics depends on physicochemical boundary conditions, so that natural limits are set. These limits are fixed by the minimum parabolic rate constants for alumina forming alloys (Fig. 2) with the hot corrosion and oxidation resistant MCrAlY coating family being the best choice [22]. The evaluation of the time required for the growth of a 10 microns thick alumina scale as a function of temperature and parabolic rate constant shows the importance of optimum composition as well as temperature control at the metal-ceramic interface. There are only few systematic investigations available on oxide growth kinetics, scale thickness and spalling of the ceramic coating under static and cyclic loading. A cyclic life prediction model has been developed recently [23]. The critical scale thickness for spallation under static thermal conditions was estimated to be around 14 microns. From own experiments it can be concluded, that i.e. the limit for cyclic thermal loading at $1000^{\circ} \mathrm{C}$ is about $10 \mu \mathrm{m}$ [24].

There is also some evidence of interaction with the zirconia of the ceramic top coating at higher temperatures [20], influencing both growth kinetics of the scale and adherence of the ceramic. However, for temperatures relevant for stationary large gas turbines, additional work has to be done.

The adherence between the bond coat and the ceramic coating is determined by the mechanical interlocking as a consequence of the original surface roughness and the chemical bonds developed through the oxidation process at the interface. Since the initial adherence is determined by the mechanical interlocking, chemical bond strength develops via temperature and time dependent reactions. Interlocking is determined primarily by the preparation and activation of the substrate surface and the spray process. Adherence tests have shown that failure occurs predominantly at the interface between TBC and bond coat in an adhesive/cohesive way. This weak area is produced during the deposition of the first layer as a consequence of the high thermal shock. With increasing coating thickness the surface temperatures increase and accordingly the surface offers more favorable adhesion conditions to the following particles.

Defects inside the coating and in the interface lead to failure in adherence and bending tests and also under thermal cyclic loading. However, it is not possible to definitely correlate the thermomechanical behavior with adhesion strengths although TBC-systems with higher adhesion strengths possess lower thermal fatigue strength [25].

\subsection{Physical Properties}

There is almost no measure to influence physical properties of the structural material and the bond coat, since materials choice follows the demands for thermomechanical properties of the component and the demands for optimum oxidation resistance for the interlayer. However, physical properties govern the additional strains (and stresses) resulting from the differences in thermal expansion, thermal conductivity and Young's modulus. The contribution of thermal expansion mismatch on cyclic life reduction is large [15]. 


\subsection{Microstructure, Morphology and Properties of Ceramic Coatings}

The morphology of the ceramic coating obviously has a profound influence on coating properties and durability. In order to achieve maximum strain tolerance of the system, controlled structures have to be achieved reproducibly by the plasma spray process. The deposition of molten ceramic droplets on the substrate surface creates a typical lamellar primary structure out of solidified droplets (Fig. 3), [25]. The lamellae exhibit a characteristic columnar structure formed by directional solidification at cooling rates between $10^{6}$ and $10^{7} \mathrm{~K} / \mathrm{s}$. The columnar grains have a few tenths of a micron in diameter and a few microns in length. Due to the disability of the particles to contract independently from their neighbours during the solidification process, micro-segmentation occurs inside the lamellae, whereby crack paths are generating between the grain boundaries. The extreme cooling rates support the formation of a fine grained structure. The grain size distribution however is nonuniform as a consequence of nonuniform temperature distribution and cooling conditions and additionally varying particle melting conditions when passing the plasma torch. Besides microcracks pores are formed within the grains and at the grain boundaries.

The properties of the ceramic coating can be modified significantly by composition and morphology. Porous, microcracked or segmented structures showed to be beneficial with respect to optimum thermomechanical properties. Porosity and microcrack networks both reduce the modulus of elasticity of the coating and further increase the fracture toughness of the system so that the development of large critical cracks may be controlled by deflection or branching etc. The wide range of variability of the Young's modulus with porosity is shown in Fig. 4 [25]. Large strains at fracture under tensile as well as compressive conditions up to about $2 \%$ can be achieved under 4-point-bending [25]. Failure was defined as spallation of TBC fragments and was detected by means of accoustic emission during bending. The actual modulus of elasticity for these ceramic coatings is somewhere between 20 to 45 $\mathrm{GPa}$. Some correlation with the measured tensile and compressive strains at fracture is shown in Fig. 5 [25].

The formation of a segmented "brush-like" structure seems to be an ideal measure to achieve optimum tensile strain tolerance. The size of the individual coating islands is determined by the shear strains in the ceramic-metal interface which transduces the tensile strains into the ceramic. There are some disadvantages to be recognized. The reversed opening and closing of the gaps can lead to additional strains, when the fit at the flanks gets worse. Segmentation cracks normal to the interface may also propagate into the structural material, when the interfacial adhesion is high enough and the coating thickness determines a crack length sufficient for subcritical crack propagation under operation conditions [26].

Fig. 6 summarizes some of the results shown above and supplemented by data for a "macrocracked" and a segmented coating. Best cyclic life was obtained for coatings with lowest modulus and highest porosity. The relevant structures are given in Fig. 7 [25].

\subsection{Residual Stress Situation}

The residual stress or better strain situation has to be taken into account when the total strain ranges of the different layers are interpreted for cyclic life determinations. They develop from the above discussed thermal expansion mismatches and depend from the thermal processing history with the temperature difference between substrate and spray deposit and the obtained cooling rate being important quantities. They also depend from the morphology of a system determining the "macroscopic" Young's modulus. A systematic investigation was completed in France in 1990 [27]. Based on a Young's modulus of $200 \mathrm{GPa}$ [28] "microscopic" residual tensile surface stresses between 30 and $100 \mathrm{MPa}$ were determined. Their magnitude is understood to depend on the morphology of the ceramic coating (e.g. size of the segments).

"Microscopic" and "macroscopic" residual stresses have been determined quite recently by Mannsmann et al. [25, 29], using a model consideration in order to conclude from microscopic to macroscopic conditions and regarding morphology, pore shapes and defects. For the as-sprayed condition, maximum values of about 20-50 MPa were determined. However, this condition changes during high temperature annealing. Significant compressive stresses occur as given in Fig. 8. This replacement of residual stresses in the system must be attributed to high temperature relaxation processes in the system (including the bond coat and the structural material) and sintering processes in the ceramic material. It is obvious, that this temperature and time dependent reversal from 
moderate tensile into high compressive stresses can contribute substantially to cyclic life reduction. Additional work is needed to quantify these effects.

\section{PROCESSING}

\subsection{Phase Composition and Morphology of Powders}

With respect to the desired phase composition of the coating, the phase composition of the spray powder may be of some relevance. The influence of the powder manufacturing process on the phase composition seems to be large. Agglomerated/sintered powders for instance showed to exist mainly of the important $t^{\prime}$-phase, whereas fused/conditioned powders showed a typical phase mixture consisting of monoclinic, tetragonal and cubic modifications [25].

There exists an important influence of the particle size, the shape and the morphology of the powders on porosity and pore size distribution. Fused/conditioned powders give denser coatings compared to agglomerated/sintered ones under similar process conditions. Increasing particle size is associated with an increase of the porosity of the ceramic spray deposit and consequently with a decrease of its Young's modulus (Fig. 9). This influence is obviously as important as the influence of process parameter variations. However, coarser particle sizes tend to give more inhomogenious pore size distributions, e.g. pore clusters. Hot spots can occur during service resulting in premature local spalling of the coating. Powder morphology, phase composition, grain size distribution and process parameters are to be matched with each other in order to achieve optimum durability.

\subsection{Process Parameters}

Multiple process parameters have to be controlled during the plasma spray process in order to achieve reproducible coating morphologies and properties. Essential parameters are

- power and current intensity of the torch

- pressure quantity and composition of plasma gases $\left(\mathrm{Ar} / \mathrm{H}_{2}, \mathrm{Ar} / \mathrm{He}\right.$ or $\left.\mathrm{Ar} / \mathrm{N}_{2}\right)$

- Pressure and quantity of the carrier gas (Ar)

- kind of powder injection into the plasma beam (inside/outside of the nozzle); injection angle, injector distance

- powder feed rate $(\mathrm{g} / \mathrm{min})$; kind of powder feed equipment (e.g. vibrator)

- spray distance and angle

- spray velocity (movement between torch and substrate).

Important are furthermore

-condition of the powder (e.g. preheating temperature, drying condition)

-substrate temperature (or cooling condition).

The influence of the most important parameters was investigated quite completely by Fischer [30, 31]. With increasing current intensity as one of the primary parameters defining the plasma conditions the density of the ceramic decreases because of increasing porosity and crack formation. The deposition rate (coating thickness) increases significantly (Fig. 10). There is a pronounced tendency for segmentation with decreasing segment sizes and the development of detrimental lateral crack nuclei originating from the segmentation cracks most probably at the interfaces of the different spray layers. The importance of the plasma gas composition was shown i.e. with a variation of the hydrogen content. As a consequence of too low plasma enthalpy and average thermal conductivity with pure Ar a deposition of zirconia was impossible. Depositon rates where sufficient at portions from $10 \%$ and more, with the coating thickness and porosity/crack formation increasing with the hydrogen content (Fig.11).

Parameters determining i.e. the melting conditions of the powder particles in the plasma flame by controlling the stay time and the amount of powder injected into the flame are the carrier gas flow and the powder feed rate. There are maxima and minima to be regarded respectively for the deposition rate (and coating thickness) and the porosity (Figs. 12,13). The higher porosities result from insufficient particle temperatures and unfavorable penetration conditions. Only with the high feed rates $>80 \mathrm{~g} / \mathrm{min}$ segmentation and some lateral crack formation could be found.

The increase of the lateral velocity of the movement of the torch (spray velocity) results in a remarkable decrease of porosity and deposition rate. The formation of segmentation cracks occurs only at low velocities and are characterized by high porosities (Fig.14). A maximum in deposition rate 
and a minimum in porosity was found by variation of the spray distance and can be explained by the formation of segmentation cracks at lower distances and an increasing real porosity with higher spray distances (Fig. 15).

\subsection{Substrate and Surface Cooling during Thermal Spraying}

Cooling of the substrate from the back or at the spray surface is an important tool to control the morphology of the ceramic coating. Surface cooling i.e. allows to realize tailored segmented structures depending from the surface temperature kept [32]. The higher the temperature the finer the segmentation. At low temperatures some porosity without any segmentation is the normal morphology.

Cooling also is an important means to optimize the residual stresses in the ceramic coating. So it is reported, that surface cooling reveals an almost stress free condition [25]. However, too low surface temperatures can lead to unfavorable spreading behavior of the molten particles and accordingly to low adhesion conditions. Too high substrate temperatures can lead to compressive stresses during cooling and thereby, depending on the bondcoat roughness and surface conditions, to crack formation in the interface and near the bond coat respectively.

\section{OUTLOOK}

Safe life under service conditions within a time period of $30.000 \mathrm{hrs}$. is still an unfulfilled requirement for the application of a thermal barrier coating as a design element in large landbased gas turbines. The relevance of specific microstructural features in order to obtain strain tolerant coatings with low residual stresses is well established. Still under discussion is whether porous, microcracked, segmented or even dense ceramic coatings will be the best choice. If one compares the properties and cyclic life data reported for columnar structured EB-PVD-coatings this discussion seems to be somewhat academic. The demand for dense but "micro"-segmented ceramic coatings is supported by the above discussed results which refer to sintering and stress redistribution processes. For optimum compressivity, however, some porosity or microcracking might be helpful. Here, more systematic work including the process parameters and the influence of spray powder properties is necessary.

Other important life determining quantities are the metal-ceramic interface properties responsible for the provision of mechanical and chemical bonds the chemical and mechanical compatibility of the system partners and the corrosion and oxidation resistance of the system. The stresses or strains which develop in the interface as a consequence of scale formation need some quantification with respect to scale thickness, strain cycles induced under realistic service load conditions and cyclic life. The maximum interface temperature is limited. This limit depends from the growth rate of the oxide scale and the allowed scale thickness within the system. Data reported for optimum MCrAlY compositions show an absolute limit to be at about $1000^{\circ} \mathrm{C}$ when the allowed scale thickness is 10 microns.

Optimum ceramic composition or amount of yttria stabilization are again discussed. The question whether 8 or 12 wt- $\% \mathrm{Y}_{2} \mathrm{O}_{3}$ will give best results is one important example. However, there is no doubt that the tough $t^{\prime}$-phase still keeps it favourable position as one important prerequisite for a strain tolerant ceramic. Open questions however offer the long time and high temperature dependant processes going on in the ceramic and probably metallic components influencing the cyclic life because of dangerous stress redistribtions, shrinkage processes, phase redistributions or corrosion induced destabilization processes.

Literature

[1] Harrison, W.N., Moore, D.G. and Richmond, J.C. NACA TN-1186, 1947

[2] Garrett, F.B. and Gyorgak, C.A., NACA RM-E 52L 30, 1953

[3] Bartoo, E.R., Clure, J.L., NACA RM-E 53E 18, 1953

[4] Shafer Jr., L.J., Stepka, F.S. and Brown, W.B., NACA RM-E 53A 19, 1953

[5] Hjelm, L.N. and Bornhorst, B.R., NASA-TM X-57072, 1961

[6] Duvall, D.S. and Ruckle, D.L., ASME Paper 82-GT-322, 1982

[7] Meitner, P.L., NASA TP-1310, 1978

[8] Khan, T., Adv. Mater. \& Proc. 1, 1990, p. 19 ff.

[9] Schulenberg, T., in "High Temperature Materials for Power Engineering 1990", Proc. Conf. Liege 1990, Kluwer

Academic Publ. 1990, pp. 903-912

[10] Gnirß, G., private communication

[11] Siemers, P.A. and Hillig, W.B., NASA CR-165351, 1981

[12] Cawley, J.D., NASA TP-2286, 1984 
[13] Toriz, F.C., Proc. Thermal Barrier Workshop at NASA Lewis, Cleveland, Ohio, 1985, pp. 187-196

[14] Singheiser, L., Stability considerations using thermodynamic data from Barin and Knacke, Springer 1977; unpublished work 1988

[15] Stecura, S., Amer. Ceram. Soc. Bull. 61, 1982, pp. 256-62

[16] Stecura, S., NASA TM 86905, 1985

[17] Miller, R.A., Smialek, J.L, Garlick, R.G., in: Advances in Ceramics, Vol. 3, Science and Technology of Zirconia, ed. A.H. Heuer and L.W. Hobbs, The American Cer. Soc., Inc., Columbus, Ohio, 1981, pp. 241-253

[18] Miller, R.A., Garlick, R.G., Smialek, J.L., Ceramic Bulletin, 62, No. 12, 1983, pp. 1355-1358

[19] Bauer, R. and Weis, J. in Fisher, FVV-Forschungsbericht 404, 1987

[20] Alperine, S. and Lelait, L., ASME Paper 92-GT-317, 1992

[21] Eaton, H.E. and Novak, R.C., Surface and Coating Technology 32, 1987, pp. 227-236

[22] Hindam, H. and Whittle, D.P., Oxid. Metals 18, 1982, p. $245 \mathrm{ff}$.

[23] Manning Meier, S., Nissley, D.M., Sheffler K.D., and Cruse, T.A., ASME Paper 91-GT-40, 1991

[24] Bürgel, R. and Schneider, K., COST 501/l Final Report D28, 1986

[25] Mannsmann, W. and Grathwohl, G., in "Beschichten und Verbinden in Pulvermetallurgie und Keramik", Pulvermetallurgie in Wissenschaft u. Praxis, Bd. 8, H. Kolaska, ed., 1992, pp. 51-81

[26] Grünling, H.W., Schneider, K. and Singheiser, L. Mater. Sci. Eng., 88, 1987, pp. 177-189

[27] Diot, C., Mevrel, R., Ochin, T. and Rio, C., ONERA Rapport Technique No 43/2019 M, 1990

[28] Zaonati, M., Ph.D-Thesis ENSAM, 1990, Ref. 10 in [27]

[29] Willmann, M.: published in [25]

[30] Fischer, U., Ph.D.-Thesis Dortmund 1989; Fortschrittsberichte VDI, Reihe 5: Grund- und Werkstoffe Nr. 171,1989

[31] Fischer, U., Forschungsberichte Verbrennungskraftmaschinen, Heft Nr. 465, 1990

[32] Johner, Wilms, ASME-TP, 88-GT-313, 1988

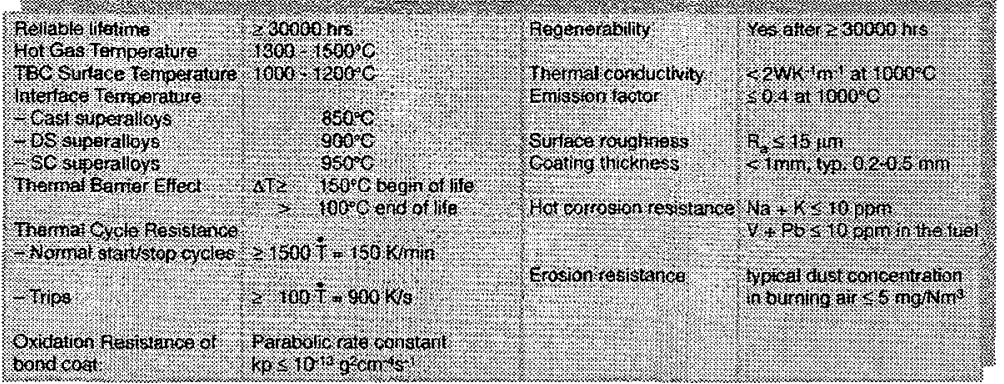

Table 1:

Some important requirements for ceramic thermal barriers in industrial gas turbine

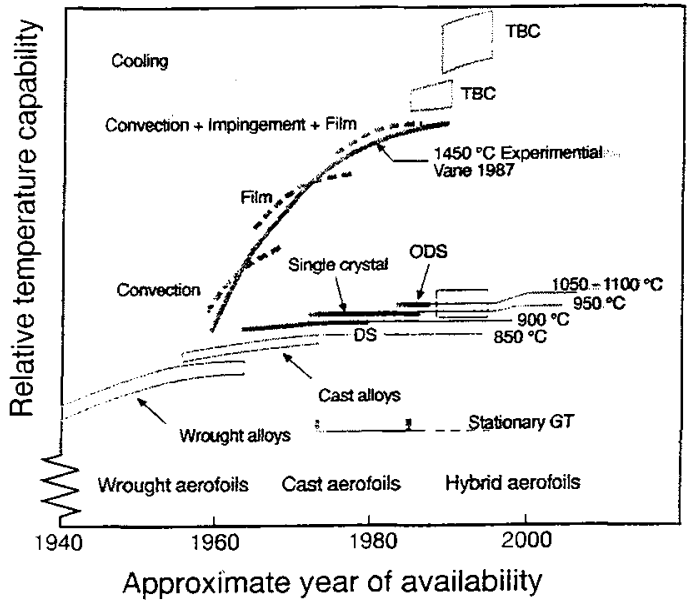

Fig1: Temperature capabilities of materials, cooled and TBC coated blades for aeroengines[8] and stationary gas turbines (supplement from Grünling, Wettstein 1990)

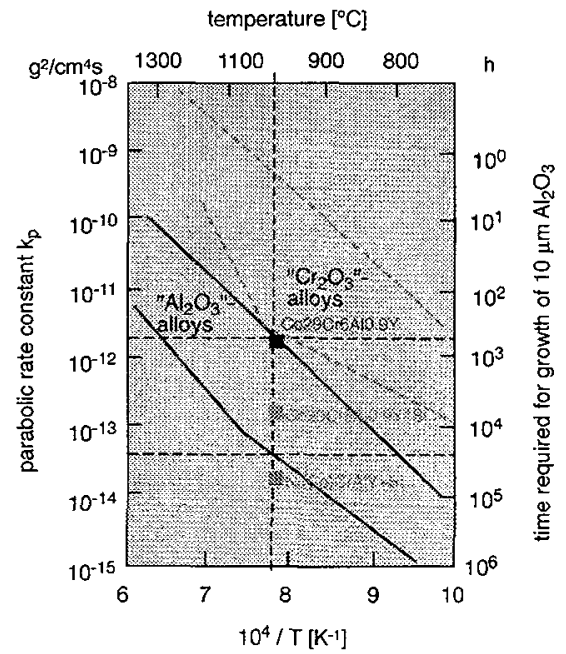

Fig 2: Parabolic rate constants for scale formation[22], data for actual coating compositions and scale growth 




Surface Structure (Thermal Etching)

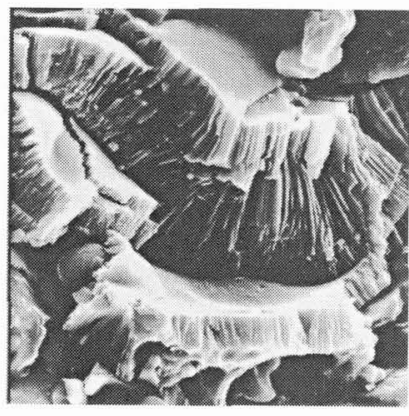

Lamellar Structure
Fig 3: Typical morphology of plasma sprayed thermal barrier coatings[25]

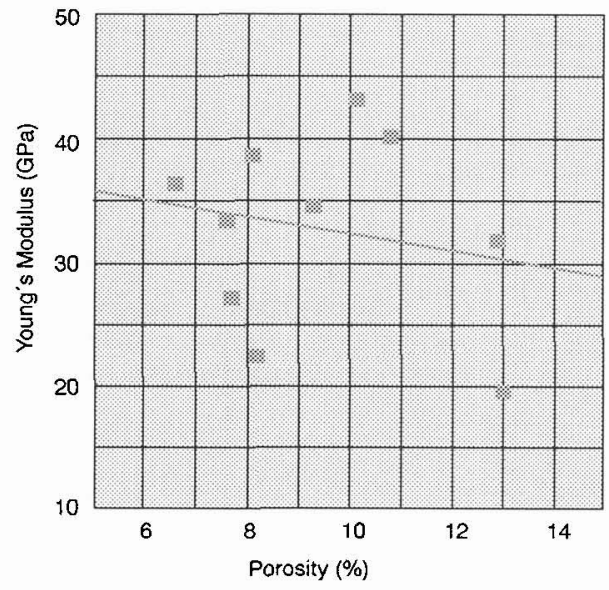

Fig 4: Relations between young's moduls and porosity in plasma sprayed TBC's[25]
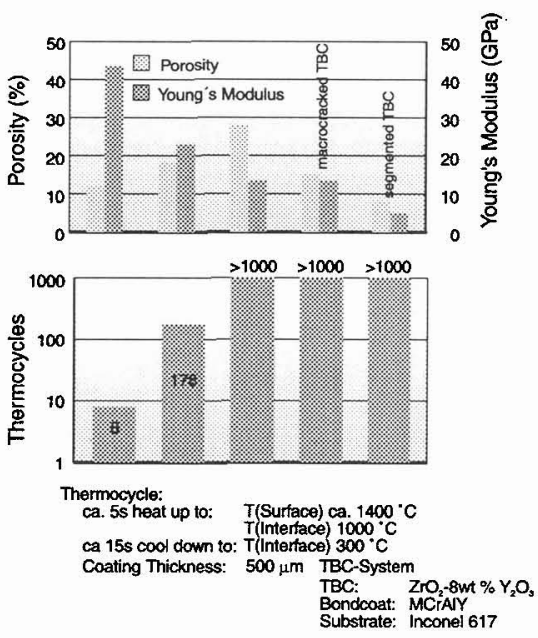

Fig 6: Porosity, young's moduls and cyclic life of TBC-systems[25] a)

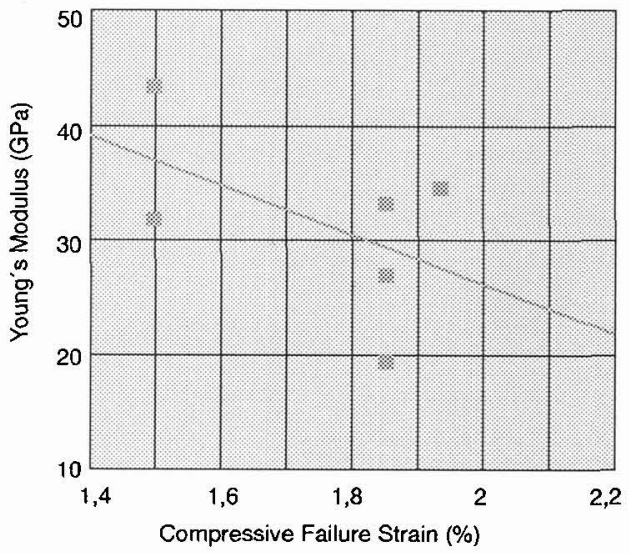

b)

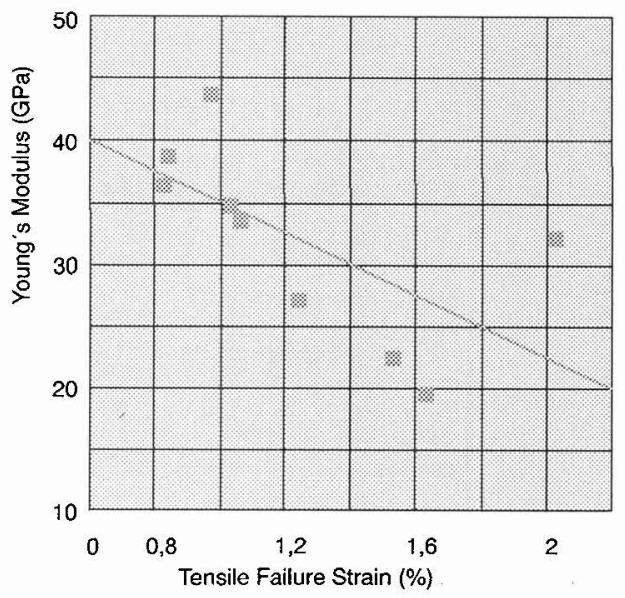

Fig 5: Young's moduls and compressive(a) and tensile(b) failure strains[25] 


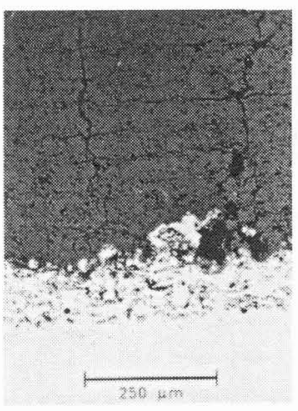

NiCrAlY Bond Coat Segmented

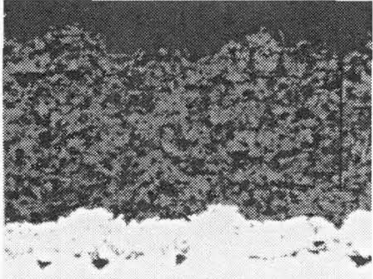

FeCrAIY Bond Coat

High Porosity

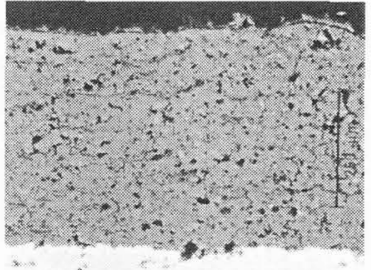

NiCrAlY Bond Coat

Macrocracked

Fig 7: Typical morphologies of plasma sprayed coatings; $\mathrm{ZrO}_{2}-8 \mathrm{wt} \% \mathrm{Y}_{2} \mathrm{O}_{3}$ with APS bond coats on IN 617[25]
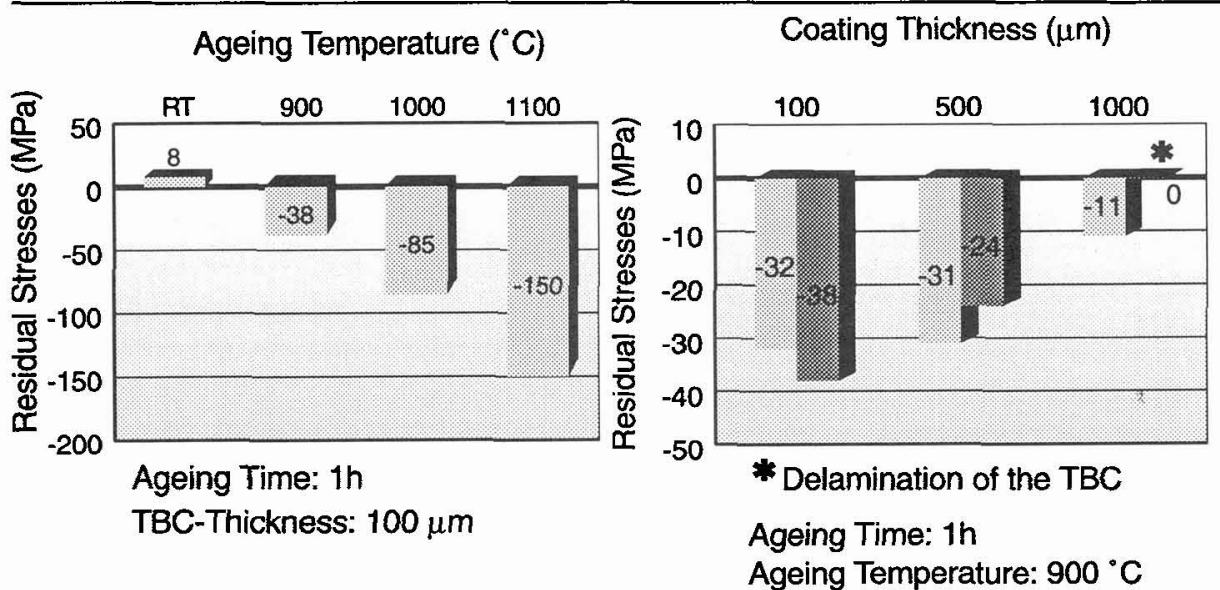

Fig 8: Residual surface stresses after isothermal annealing[25]

\section{Spray Powder Fraction}

Fig 9: Influence of powder fraction and process parameters on porosity and young's moduls[25]

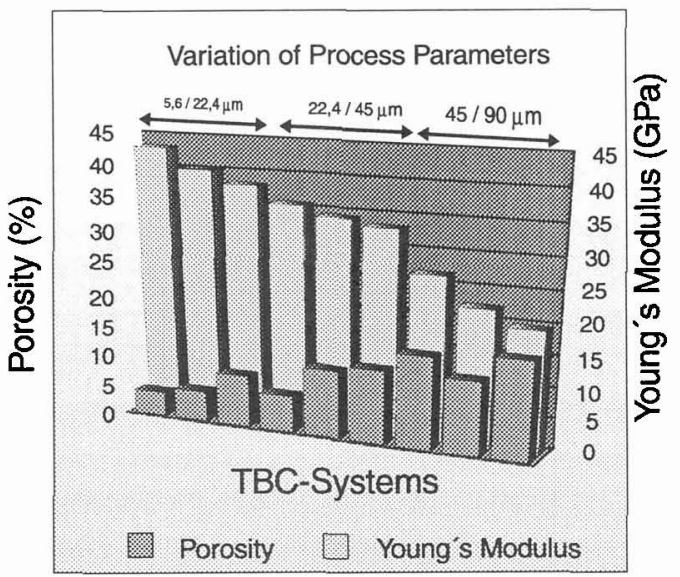

TBC-System:

TBC:

Bondcoat:

Substrate:

$\mathrm{ZrO}_{2}-8 \mathrm{wt} \% \mathrm{Y}_{2} \mathrm{O}_{3}$ 


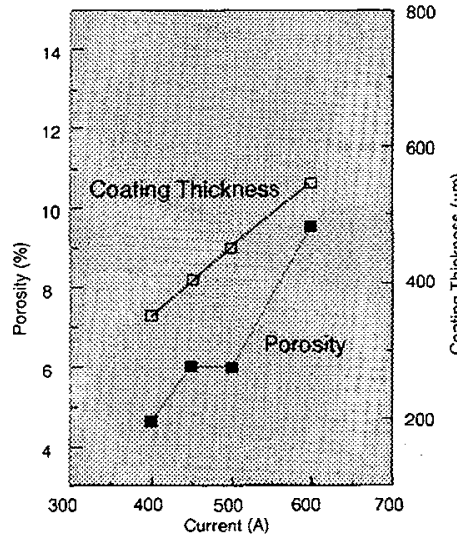

$\begin{array}{lrl}\text { Content of Hydrogen } & 10,0 & \mathrm{l} / \mathrm{min} \\ \text { Carrier Gas Flow } & 6,0 & \mathrm{l} / \mathrm{min} \\ \text { Spray Distance } & 80 & \mathrm{~mm} \\ \text { Powder Feed Rate } & 60 & \mathrm{~g} / \mathrm{min} \\ \text { Spray Velocity } & 0,3 & \mathrm{~m} / \mathrm{s}\end{array}$

Fig 10:

Influence of current intensity[30]
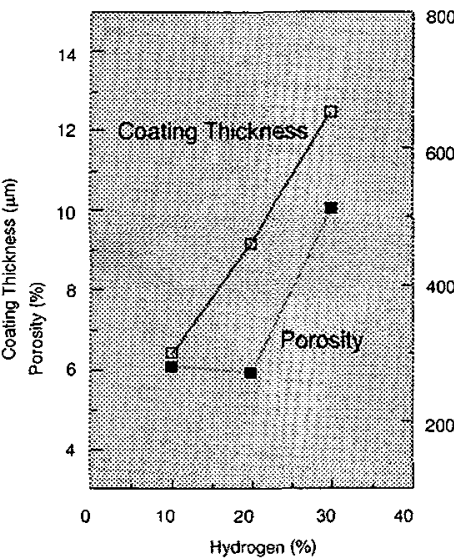

Current

Carrier Gas Flow

$500 \mathrm{~A}$

Spray distance

Powder Feed Rate

Spray Velocity

Fig 11:

Influence of hydrogen content in the primary gas[30]

$6,0 \mathrm{l} / \mathrm{min}$

$80 \mathrm{~mm}$

$60 \mathrm{~g} / \mathrm{min}$

$0,3 \mathrm{~m} / \mathrm{s}$

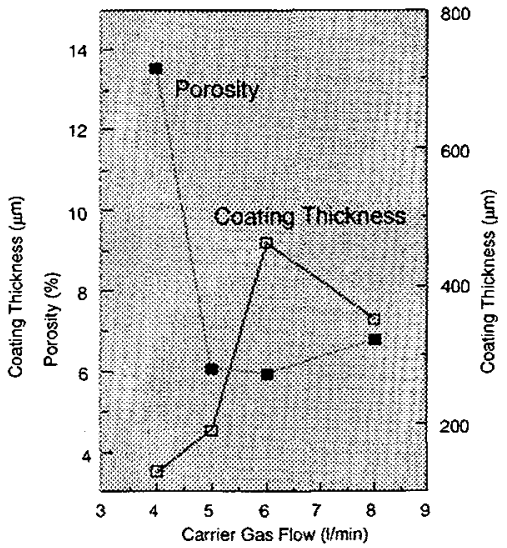

Current

$500 \mathrm{~A}$

Content of Hydrogen $10,0 \quad \mathrm{l} / \mathrm{min}$

Spray distance

$80 \mathrm{~mm}$

Powder Feed Rate

$60 \mathrm{~g} / \mathrm{min}$

Spray Velocity

$0,3 \mathrm{~m} / \mathrm{s}$

Fig 12:

Influence of carrier gas flow[30]

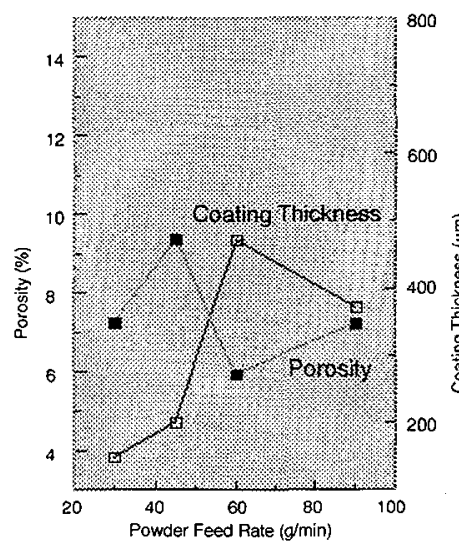

Current

Content of Hydrogen $10,0 \mathrm{I} / \mathrm{min}$

Carrier Gas Flow $\quad 6,0 \quad \mathrm{l} / \mathrm{min}$

Spray Distance

Spray Velocity

$80 \mathrm{~mm}$

$0,3 \mathrm{~m} / \mathrm{s}$

Fig 13:

Influence of powder feed rate[30]

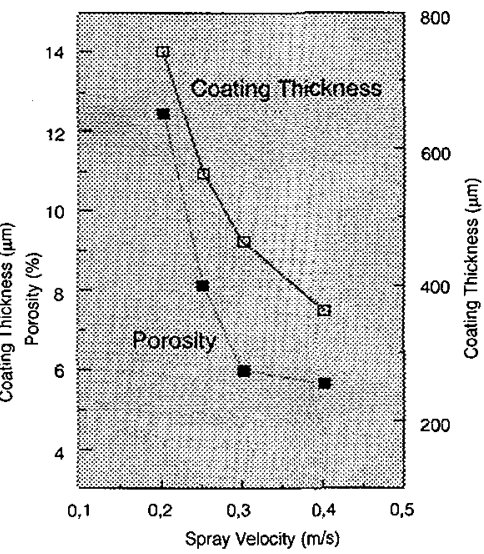

Current $\quad 500 \mathrm{~A}$

Content of Hydrogen $10,0 \quad \mathrm{l} / \mathrm{min}$

Carrier Gas Flow $\quad 6,0 \quad \mathrm{l} / \mathrm{min}$

Spray Distance $\quad 80 \mathrm{~mm}$

Powder Feed Rate $\quad 60 \mathrm{~g} / \mathrm{min}$

Fig 14:

Influence of spray velocity[30]

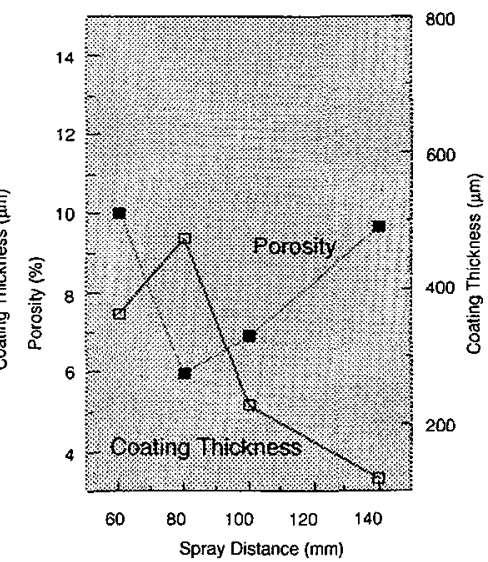

Current $\quad 500 \mathrm{~A}$

Content of Hydrogen $\quad 10,0 \quad 1 / \mathrm{min}$

Carrier Gas Flow $\quad 6,0 \mathrm{l} / \mathrm{min}$

Powder Feed Rate $\quad 60 \mathrm{~g} / \mathrm{min}$

Spray Velocity $\quad 0,3 \mathrm{~m} / \mathrm{s}$

Fig 15:

Influence of spray distance[30] 